\title{
Assessment of the ecological state of the territory by its population in the context of the formation of environmental awareness (on the example of a small town)
}

\author{
Irina Zaitseva*, and Aleksander Krikunov \\ Bunin Yelets State University, Kommunarov Str., 28, 399770 Yelets, Russia
}

\begin{abstract}
The article analyzes the assessment of the ecological state of the territory by its population in a small town to study the state of public environmental awareness. According to official data, the city of Yelets and the Lipetsk region in general face a significant number of unresolved environmental problems against the background of a quite stable ecological situation. Given the general complex ecological situation in the region, the assessment of the ecological situation in specific settlements, rooted in the local agenda, can be radically different. This allows us to speak about the primary attention of the population to their local place of residence and the problems they face directly. The involvement of the population in the activities to preserve the environment of the region as a whole requires promoting public environmental awareness through a competent environmental policy by state and municipal authorities.
\end{abstract}

\section{Introduction}

No matter how we interpret the idea of sustainable development in the context of practical steps to implement the supposed prospect of improving social institutions, its general focus on harmonizing the relationship between man and nature leaves the improvement of the ecological situation among the main priorities, even against the background of increased attention to recent social issues $[1,2]$. The importance of this component is also determined by a special perspective on the consideration of environmental issues, accompanied by the appropriate language that supports the narrative of human-inspired deterioration of environmental conditions, climate change, and the depletion of non-renewable natural resources.

The measurement of the characteristics of the ecological situation, reflected by the currently existing sets of indicators of sustainable development [3, 4], is focused on monitoring the immediate state of the environment. It includes the volume of groundwater reserves, the degree of soil erosion, the rate of deforestation, etc. The use of sociological procedures in such a context naturally shifts the emphasis to the very attitude to the environment shown in certain social groups. It can be reasonably assumed that to the extent

\footnotetext{
${ }^{*}$ Corresponding author: zaitsevairin@mail.ru
} 
that the sustainable development of the territory is due to the preservation of the environment and the optimization of its use, it is the attitude of society to environmental issues that makes it possible to judge the prospects for the preservation and development of nature conservation practices [5-7]. Sociology in this case helps to move from theoretical reasoning about the attitude of society to environmental problems to the direct recording of the assessments made and the actions they produce as manifestations of public environmental awareness [8].

Specific studies of this kind provide an insight into the specifics of the attitude to the ecological component of sustainable development, which is characteristic of different types of settlements and territories. Within the framework of this study, the object is the population of a small town, which demonstrates specific refraction of the general trends characteristic of the country at the beginning of the XX century. We seem it essential to consider the assessment by the population of the ecological state of the territory in the context set by the formal assessment of the problems of the natural environment of the region and the forms of significant anthropogenic impact on it.

\section{Material and Methods}

The study used the necessary set of theoretical and empirical methods. Theoretical methods were analysis of scientific literature on sustainable development, and study and generalization of assessments of the environmental situation in the Lipetsk region and the city of Yelets. Empirical data were collected as part of the assignment of the Department of Ecology and Natural Resources of the Lipetsk region, which involved a socio-political study to assess the level of environmental awareness of the population of the Lipetsk region [9]. The study was carried out in 2019 at I.A. Bunin YSU. Data was collected with the help of a formalized questionnaire survey using non-random (spontaneous) sampling. The total number of respondents was 185 people (residents of Yelets, aged 18 and older). Data processing and analysis were carried out in SPSS 22.0. The following statistical procedures were used for the analysis: descriptive statistics; contingency tables.

\section{Results and Discussion}

The relevance of preserving the environment in the Lipetsk region is dictated by the tension of the ecological situation in the region in areas with intensive industrial and other economic activity [10].

The degree of air pollution in the Lipetsk region is determined by the emissions of pollutants into the air from stationary and mobile sources (vehicles). The total emissions of pollutants into the air from stationary sources in the Lipetsk region in 2018 amounted to 326.4 thousand tons. The main air pollutant in the region is the Novolipetsk Metallurgical Plant (Lipetsk) [10]. Emissions of harmful substances in the city of Yelets, Lipetsk region, in 2018 amounted to 2,506 tons/year, in the city of Lipetsk - 2,846 tons/year.

Lipetsk region is one of the regions provided with water resources, the use of which is constantly expanding. According to the data of the department of water resources for the Lipetsk region, the Don Basin Water Administration in 2018, the total water intake from surface and groundwater bodies increased by 6.83 million $\mathrm{m}^{3}$ and amounted to 193.01 million $\mathrm{m}^{3}$ [10].

As of 01.01.2019, 188 specially protected natural areas (SPNA) were formed on the territory of the Lipetsk region. The current state of natural complexes, as well as rare species of flora and fauna, is stable, however, the main negative factors affecting the 
ecosystems are spontaneous landfills, unregulated recreation, development of areas adjacent to natural monuments, aging of parks.

At the end of 2018, the region generated 2,581.8 thousand $\mathrm{m}^{3}$ of solid municipal waste (MSW), of which 2,552.2 thousand $\mathrm{m}^{3}$ were sent for landfilling.

The most significant negative factor in the districts of the region and the city of Lipetsk is the pollution of drinking water (the contribution to the integrated man-made burden index (IMMBI) in the region is 43.84\%) [10]. The main pollutants of drinking water in the region are nitrates, iron, manganese, boron, fluorine; it is also characterized by high hardness.

The high man-made burden is the reason for persisting soil pollution. In the region, the share of chemical soil contamination in KPATN was $23.06 \%$. The highest pollution index is noted in the city of Yelets (66.6\%) [10].

According to official data, the ecological situation in the region remains stable but with many significant problems. Among the main ones are air pollution as a result of emissions from industrial enterprises and vehicles, pollution of water resources of the region by industrial enterprises, housing and communal services and agriculture, formation and accumulation of production and consumption waste, soil pollution, desertification, and degradation of vegetation cover, and reduction in the species composition of flora and fauna. It is of interest to compare this assessment with the assessment of the ecological situation given by the residents of the region and its settlements and territories, which, in a certain sense, will make it possible to speak about the degree of environmental awareness, which in the future can become a factor influencing the nature of the use of natural resources of the region.

A special survey of residents of the city of Yelets made it possible to draw several conclusions.

It is indicative that most of the respondents (70.2\%) assessed the environmental situation in general as acceptable or favorable (Fig. 1). The distribution of answers, however, should be interpreted rather carefully, considering the positive emotional background created by the information of the official media, on the one hand, and the significant de-industrialization of the city, on the other. However, regardless of the factors that could cause its appearance, we can quite reasonably state a fairly high degree of satisfaction of the population with the general environmental situation.

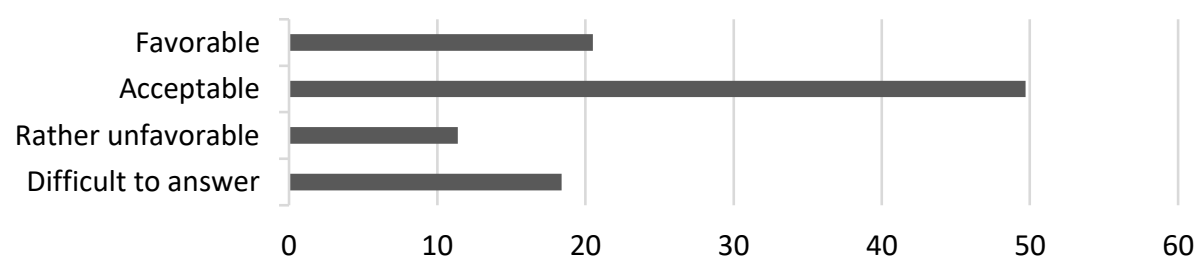

Fig. 1. Distribution of respondents' answers to the question "How do you assess the environmental situation in your place of residence?" (one answer, \%)

The same is evidenced by the choice of the most significant environmental problems by the respondents (Fig. 2). The answers were distributed more or less evenly, which means the respondents had no reason to point out an obvious, ill-disguised problem. The above distribution of answers can hardly provide an insight into the general deterioration of the ecological situation. It is worth noting that global air and water pollution, the disappearance of green spaces are less of a problem for respondents than the growth of landfills being witnessed by the population. In this sense, which is confirmed by the answers to the subsequent questions, the formation of environmental problems is based, rather, on direct impressions arising in the context set by everyday life and relations with local authorities. 
In the future, it would be interesting to establish the extent to which the value of jobs generated by manufacturing enterprises in itself contributes to the exclusion of the industrial sector from the number of priority local sources of environmental hazards for the population.

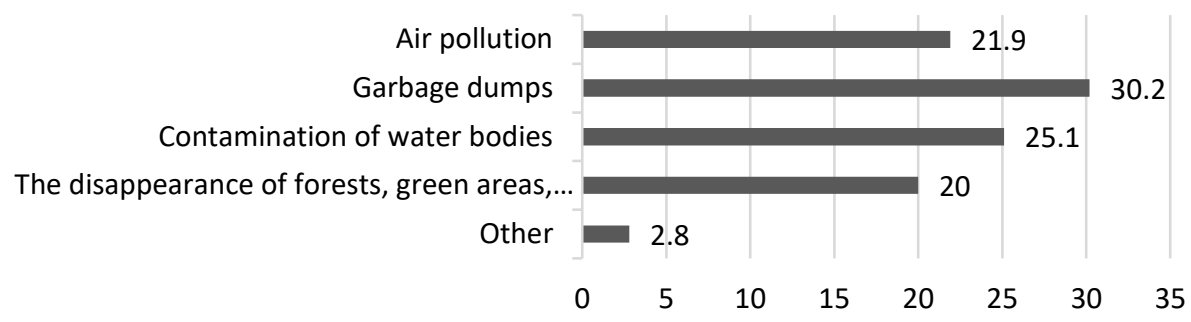

Fig. 2. Distribution of respondents' answers to the question "What environmental problem is of your particular concern today?" (one answer, \%)

An attempt to assess changes in the ecological state of the environment over the past 2-3 years also indicates a relatively low percentage of people who consider it possible to talk about a worsening of the situation (18.9\%) against the background of $27 \%$ of respondents who note its improvement. At the same time, $15.7 \%$ indicated that, from their point of view, the situation has remained unchanged, and more than a third of the respondents (38.4\%) found it difficult to assess the changes. The latter figure seems to us the most indicative of the extent to which the respondents are ready to consider their overall assessment of the environmental situation as the result of careful monitoring of changes in the environmental situation.

This is confirmed by the respondents' assessment of the degree of their environmental awareness. Relatively few respondents are indifferent to ecology $(10.8 \%)$ or considered themselves to be well-informed (16.2\%). 39.5\% of the respondents answered that they have not been well informed, and $33.5 \%$ chose the "superficial" option, which in total amounts to more than two-thirds of the sample. The figures should be interpreted not only as a reason for additional efforts concerning informing the population but also as a result of the general attitude of the population to environmental issues recorded at the local level, especially if the question does not specify the problems and does not indicate directly to human-directly related environmental challenges.

The distribution of preferable sources of information (Fig. 3) showed, on the one hand, still the great importance of television, on the other hand, the even higher importance of the Internet, which, however, in a real small city, largely duplicates news from traditional media.

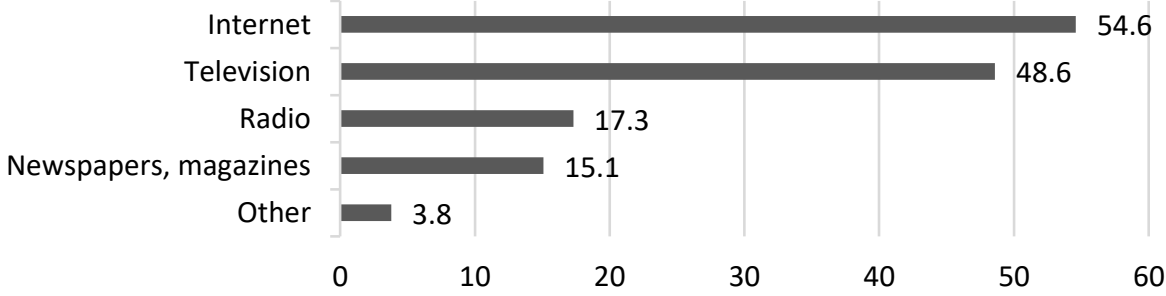

Fig. 3. Distribution of respondents' answers to the question "What sources do you prefer to get reliable information from about the ecological situation?" (multiple choice, \%) 
The answers to the question on the responsibility for improving the ecological situation were distributed almost evenly (Fig. 4), which does not indicate a clearly defined tendency. Rather, they, again when the problem is blurred, testify to the assimilation of the entire spectrum of opportunities provided by describing the current environmental problems, including an indication of the extremely general "culture and education of the population" (the most popular answer). The proposed options practically exhausted the possibilities considered by the respondents, as evidenced by the insignificant percentage of the offer of their options $(3.8 \%)$.

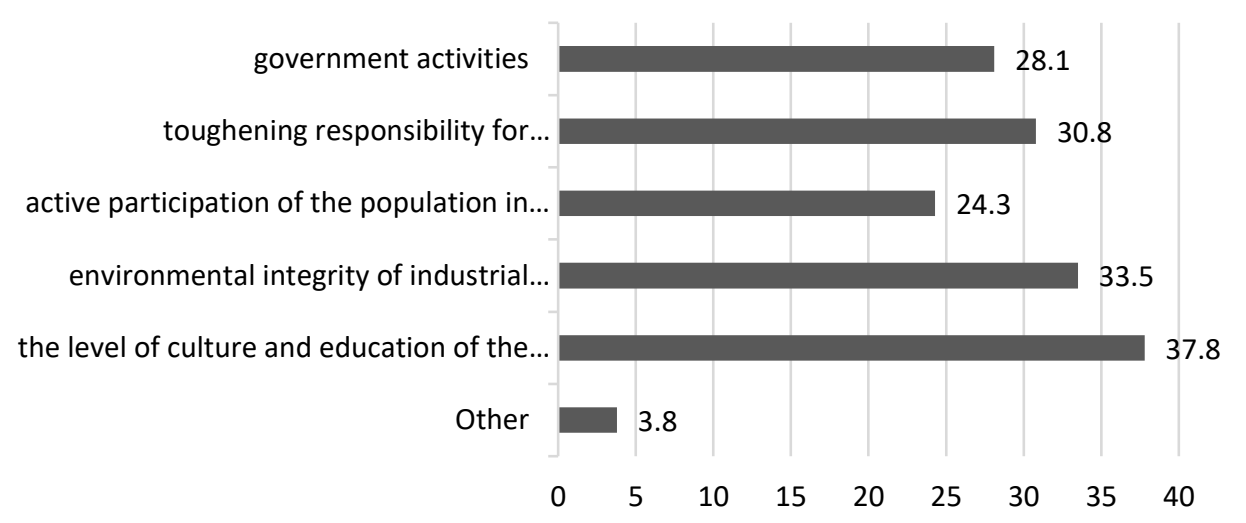

Fig. 4. Distribution of respondents' answers to the question "What, in your opinion, does the improvement of the ecological situation depend on?" (multiple choice, \%)

The respondents were also asked about their possible reaction to environmental violations, showing that more than half of the respondents, at least potentially, are ready to take some action in this case (Fig. 5).

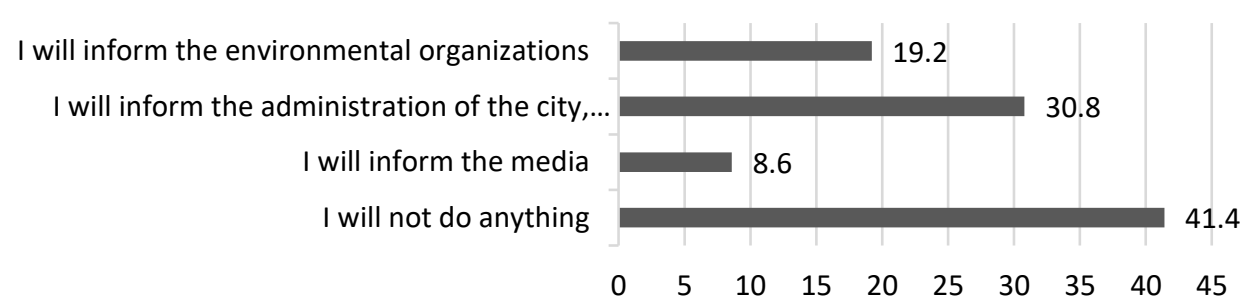

Fig. 5. Distribution of respondents' answers to the question "What will you do if you witness an environmental offense?" (one answer, \%)

\section{Conclusion}

Thus, subject to the general deterioration of the environment in the region, the assessment of the ecological situation in specific settlements, rooted in the local agenda, may be different. This indicates the predominant attention of the population to the local place of residence. Public interest in environmental issues is situational. The population sees environmental problems as something associated with the current state of the environment. The environmental awareness of the population cannot be defined as ecocentric (ecologically-focused). Residents of Yelets are concerned about the state of the 
environment, realize their responsibility for its deterioration, and the need for environmental education but at the same time place the main burden of responsibility for environmental problems on the authorities. As a possible reason for the insufficient level of environmental awareness among the population, one can name an insufficiently effective information policy. State and municipal authorities should use new tools for the development of public environmental awareness. For example, the introduction of a new information strategy, the concept of which is to use social networks as a communication platform for municipal authorities and the population on the city's ecology.

\section{References}

1. 2020 Sustainable Development Goals Report. United Nations (2020)

2. J.D. Sachs, The Age of Sustainable Development (2015)

3. H. Bossel, Indicators for sustainable development: Theory, method, applications (1999)

4. J. Hickel, Ecological Economics, 167, 106331 (2020)

5. V. Kalner, Ecology and Industry of Russia, 23, 50 (2019)

6. G.S. Rozenberg, G.E. Kudinova, A.V. Vasiliev, L.R. Khamidullova, V.A. Sazhnev, I.P. Shimanchik, Ecology and Industry of Russia, 6, 32 (2012)

7. D.G. Domrachev, A.A. Kirillovykh, V.N. Pugach, Theoretical and applied ecology, 2, 187 (2020)

8. I. N. Karpova, PSU Bulletin, 21, 263 (2011)

9. Report on research "The level of awareness of the population of the Lipetsk region about the "Environmental protection, reproduction and rational use of natural resources of the Lipetsk region" program". Department of Ecology and Natural Resources of the Lipetsk Region (2019)

10. Environmental state and protection in the Lipetsk region in 2018. The Report (2019) 